\title{
Heat-mass transfer efficiency within the cooling towers with jet-film contact devices
}

\author{
Ilnur N. Madyshev ${ }^{1}$, Oksana S. Dmitrieva ${ }^{2}$, and Andrey V. Dmitrieve, ${ }^{2,}$ \\ ${ }^{1}$ Kazan National Research Technological University, 420016 Kazan, Russia \\ ${ }^{2}$ Kazan State Power Engineering University, 420066 Kazan, Russia
}

\begin{abstract}
Jet-film contact devices with special design elements for intensification of heat-mass transfer processes are proposed. An experimental apparatus has been created in order to study the interaction of water and air flows within these devices. It has been revealed that an increase in the ratio of mass flow rate of liquid and gas phases leads to a decrease in heat efficiency coefficient. Within the area of high values of specific loads, an increase in the local minimum of mass transfer efficiency is observed.
\end{abstract}

\section{Introduction}

Circulation water supply systems are one of the most important elements of technological complex at industrial enterprises and CHP plants. At the same time, efficiency of cooling the circulating water within the cooling towers depends largely on even distribution of the contact phases in the volume of nozzle [1].

Studies of the hydrodynamic situation within the current designs of contact devices reveal uneven distribution of liquid and gas phases in the cross section of the nozzle area, which prevents the intensification of heat-mass transfer processes and reduces the depth of cooling the circulating water.

Searching for the ways to intensify the heat-mass transfer within gas-liquid systems led to the development of fundamentally new apparatuses with vertical grids, drop-film sprinklers, and regular nozzles of increased throughput capacity [2-6]. According to the analysis of the most promising designs of contact devices, developed in recent years, each new design solution gives a slight gain in efficiency. The designs are mostly becoming more and more complex $[7,8]$.

\section{Description of jet-film contact device}

The jet-film contact devices [9], allowing self-distribution of the flowing liquid phase over the cross section of the apparatus, are developed. One of the modifications of contact device is shown in Fig. 1. The proposed device consists of parallel square drain cups 1 with vertical walls, required for maintaining the liquid level inside of them. Vertical corrugated

\footnotetext{
* Corresponding author: ieremiada@gmail.com
} 
and perforated baffles 2 are the supports for drain cups 1 and have slotted holes for the installation of appropriate drain cups 1 . The drain cups 1 are open from the top end, but recurved leaves 3 in the form of circular segments are executed in the bottom of cups. These segments are required for the liquid distribution over the surface of vertical corrugated and perforated baffles 2 .

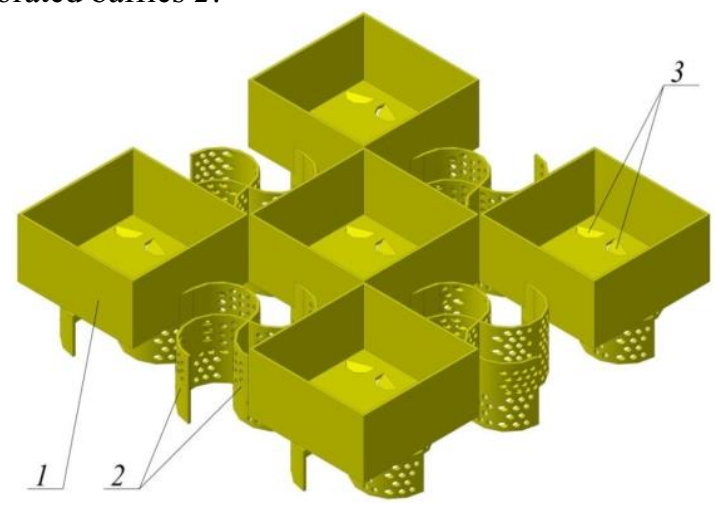

Fig. 1. Jet-film contact device: 1 - drain cup; 2 - corrugated and perforated baffles; 3 - recurved leaves.

The jet-film contact device, developed by the authors, operates as follows. Liquid, through the plurality of recurved leaves 3 , executed in the bottom of drain cups 1 , is dispersed in the form of jets to the below located vertical corrugated and perforated baffles 2. When liquid jets move along the surface of vertical baffles 2, the liquid is distributed with formation of a stable film flow. Thus, the coming down liquid film interacts with an ascending gas flow. After that the formed film, colliding with liquid surface inside of drain cups 1 , collapses. When distances between the drain cups, arranged at the same level, are equal to width of a drain cup, it provides stable, uniform gas flow, which leads to decrease in hydraulic resistance of the proposed jet-film contact device. Thus, organization of original interaction between gas and liquid allows stimulating the heat-mass transfer processes both in liquid and in gas phases at relatively simple design of apparatus.

\section{Analysis of results of experimental research}

Experimental research has been carried out in order to determine the efficiency of heatmass transfer within the contact stage of jet-film device with corrugated and perforated baffles. Holes with a diameter of $5 \mathrm{~mm}$ were executed on each baffle and located on tops of equilateral triangles with a step of $7.5 \mathrm{~mm}$ between the holes. Average air flow rate for the full cross-section of empty apparatus was varied in the range of $1.06-3.07 \mathrm{~m} / \mathrm{s}$; irrigation density $-11.0-44.85 \mathrm{~m}^{3} / \mathrm{m}^{2} \cdot \mathrm{h}$, temperature of the cooling air $-21.2-21.5^{\circ} \mathrm{C}$; hot water temperature $-44.2-50.9^{\circ} \mathrm{C}$. The relative air humidity during the experiment was $70 \%$. In order to measure the temperature and relative air humidity at the inlet and outlet of contact stage, thermal hygrometer Testo 605i was used. Water temperature at the inlet and outlet of contact stage was measured by a two-channel regulator OVEN. Liquid flow rate was measured by variable-area flowmeter; the air flow velocity was measured by thermal anemometer Testo $405 \mathrm{i}$ with a relative error of not more than $5 \%$.

The degree of improving the heat-mass transfer processes within the evaporative water cooler is usually characterized by the value of temperature coefficient (heat efficiency coefficient) [10]: 


$$
\eta_{L}=\frac{t_{L 0}-t_{L k}}{t_{L 0}-t_{L p}},
$$

where $t_{L 0}$ - water temperature at the inlet of contact stage, ${ }^{\circ} \mathrm{C} ; t_{L k}$ - water temperature at the outlet of contact stage, ${ }^{\circ} \mathrm{C} ; t_{L p}-$ equilibrium water temperature, i.e. dew-point temperature (theoretical limit of water cooling), ${ }^{\circ} \mathrm{C}$.

It is known from early studies [11-13] that proportion of heat transfer by evaporation within evaporative water coolers is very high, thus, the heat balance equation with sufficient accuracy (without taking into account heat conductivity, convection and vapor condensation) can be recorded as follows:

$$
Q=L_{m} c_{L}\left(t_{L 0}-t_{L k}\right)
$$

where $L_{m}$ - mass water flow rate, $\mathrm{kg} / \mathrm{s} ; c_{L}$ - mass specific heat of water, $\mathrm{J} /(\mathrm{kg} \cdot \mathrm{K})$.

The material balance (moisture balance) is determined by the equality between the amount of evaporated liquid and the increase in the moisture content of the air:

$$
\Delta L_{m}=G_{m}\left(x_{k}-x_{0}\right)
$$

where $G_{m}$ - mass air flow rate, $\mathrm{kg} / \mathrm{s} ; x_{0}, x_{k}$ - moisture content of saturated air at the inlet and outlet of contact stage, $\mathrm{kg} / \mathrm{kg}$.

On the other hand, the amount of evaporated liquid can be determined by the equation:

$$
\Delta L_{m}=\frac{Q}{r},
$$

where $r$-evaporation specific heat, $\mathrm{J} / \mathrm{kg}$.

Then the moisture content of saturated air at the outlet of contact stage can be determined as follows:

$$
x_{k}=x_{0}+\frac{\Delta L_{m}}{G_{m}},
$$

Thus, mass transfer efficiency coefficient of contact stage can be determined by the change in the moisture content of saturated air, assuming that the entire heat flow is consumed for the water evaporation:

$$
E=\frac{x_{k}-x_{0}}{x_{p}-x_{0}},
$$

where $x_{p}$ - equilibrium moisture content of saturated air, $\mathrm{kg} / \mathrm{kg}$.

The scheme in Fig. 2a shows that an increase in the ratio of mass flow rate of liquid and gas phases leads to a decrease in heat efficiency coefficient. When the irrigation densities are relatively low, the heat efficiency coefficient of contact stage can reach $37.5 \%$. Within the area of high specific loads $\mathrm{Lm} / \mathrm{Gm}$, an increase in the local minimum of mass transfer efficiency is observed (Fig. 2b). For example, an increase in the irrigation density from 11.0 up to $44.85 \mathrm{~m}^{3} / \mathrm{m}^{2} \cdot \mathrm{h}$ leads to an increase in the average efficiency from 31 up to $60 \%$. Further increase in mass transfer efficiency coefficient is due to the fact that the rate of increase in the amount of evaporated liquid prevails over the rate of increase in mass air flow rate. 

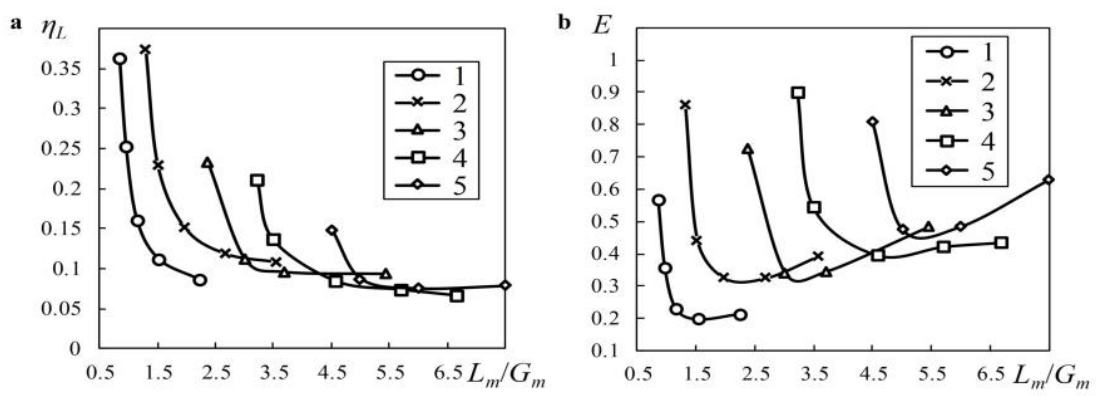

Fig. 2. Dependency of the change in heat (a) and mass (b) transfer efficiency coefficient of contact stage on ratio of mass flow rate of liquid and gas phases at different irrigation densities $q, \mathrm{~m}^{3} / \mathrm{m}^{2} \cdot \mathrm{h}$ : $1-11.0 ; 2-17.43 ; 3-24.3 ; 4-36.7 ; 5-44.85$.

\section{Conclusion}

The conducted experimental research shows that the developed jet-film contact devices have a sufficiently high efficiency of heat-mass transfer, but, at the same time, modes, corresponding to a relatively low hydraulic resistance, should be chosen when conducting the processes. Thus, it can be stated that the use of the proposed contact devices at industrial enterprises and in the energy sector will ensure a decrease in the temperature of the cooled water within the cooling towers at low operating costs.

The research was conducted with funding from the grant of RF President No. MK-4522.2018.8.

\section{References}

1. A. G. Laptev, V. A. Danilov, I. V. Vishnyakova, Therm. Eng. 51, 661 (2004)

2. E. V. Boev, S. P. Ivanov, V. G. Afanasenko, E. A. Nikolaev, Chem. Pet. Eng. 45, 454 (2009)

3. J. Lee, Nucl. Eng. Des. 326, 65 (2018)

4. S. P. Fisenko, A. I. Petruchik, A. D. Solodukhin, Int. J. Heat Mass Transfer 45, 4683 (2002)

5. O. S. Dmitrieva, A. V. Dmitriev, A. N. Nikolaev, Chem. Pet. Eng. 50, 169 (2014)

6. V. G. Afanasenko, F. Sh. Khafizov, N. F. Khafizov, S. P. Ivanov, E.V. Boev, Chem. Pet. Eng. 43, 653 (2007)

7. O. S. Dmitrieva, A. V. Dmitriev, I. N. Madyshev, A. N. Nikolaev, Chem. Pet. Eng. 53, 130 (2017)

8. C. Zheng, X. Chen, L. Zhu, J. Shi, Energy 150, 653 (2018)

9. A. V. Dmitriev, O. S. Dmitrieva, I. N. Madyshev, A. N. Nikolaev, L. V. Kruglov, Patent RU No. 171022 (2017)

10. F. Kreith, R.F. Boehm, Heat and Mass Transfer (CRC Press LLC, Boca Raton, 1999)

11. G. V. Kuznetsov, D. V. Feoktistov, E. G. Orlova, S. Y. Misyura, V. S. Morozov, A.G. Islamova, Int. J. Heat Mass Transfer 126, 161 (2018)

12. Y. Li, X. You, Q. Qiu, J. Li, Energy Convers. Manage. 52, 53 (2011)

13. G. V. Kuznetsov, D. V. Feoktistov, E. G. Orlova, J. Eng. Phys. Thermophys. 89, 317 (2016) 